\title{
Rap1 relocalization contributes to the chromatin-mediated gene expression profile and pace of cell senescence
}

\author{
Jesse M. Platt, ${ }^{1}$ Paul Ryvkin, ${ }^{1,2}$ Jennifer J. Wanat, ${ }^{1}$ Greg Donahue, ${ }^{3}$ M. Dan Ricketts, ${ }^{4}$ Steven P. Barrett, ${ }^{5}$ \\ Hannah J. Waters, ${ }^{1}$ Shufei Song, ${ }^{1}$ Alejandro Chavez, ${ }^{1,6}$ Khaled Omar Abdallah, ${ }^{1,7}$ Stephen R. Master, ${ }^{1}$ \\ Li-San Wang, ${ }^{1,2}$ and F. Brad Johnson ${ }^{1,8}$ \\ ${ }^{1}$ Department of Pathology and Laboratory Medicine, University of Pennsylvania, Philadelphia, Pennsylvania 19104, USA; ${ }^{2}$ Penn \\ Institute for Biomedical Informatics, University of Pennsylvania, Philadelphia, Pennsylvania 19104, USA; ${ }^{3}$ Department of Cell \\ and Developmental Biology, University of Pennsylvania, Philadelphia, Pennsylvania 19104, USA; ${ }^{4}$ Wistar Institute, Philadelphia, \\ Pennsylvania 19104, USA; ${ }^{5}$ Department of Chemistry and Biochemistry, Swarthmore College, Swarthmore, Pennsylvania \\ 19081, USA
}

Cellular senescence is accompanied by dramatic changes in chromatin structure and gene expression. Using Saccharomyces cerevisiae mutants lacking telomerase (tIc1S) to model senescence, we found that with critical telomere shortening, the telomere-binding protein Rap1 (repressor activator protein 1) relocalizes to the upstream promoter regions of hundreds of new target genes. The set of new Rap1 targets at senescence (NRTS) is preferentially activated at senescence, and experimental manipulations of Rap1 levels indicate that it contributes directly to NRTS activation. A notable subset of NRTS includes the core histone-encoding genes; we found that Rap1 contributes to their repression and that histone protein levels decline at senescence. Rap1 and histones also display a target site-specific antagonism that leads to diminished nucleosome occupancy at the promoters of upregulated NRTS. This antagonism apparently impacts the rate of senescence because underexpression of Rap1 or overexpression of the core histones delays senescence. Rap1 relocalization is not a simple consequence of lost telomere-binding sites, but rather depends on the Mec1 checkpoint kinase. Rap1 relocalization is thus a novel mechanism connecting DNA damage responses (DDRs) at telomeres to global changes in chromatin and gene expression while driving the pace of senescence.

[Keywords: cellular senescence; telomere; Rap1; histones; chromatin; PI3-like kinase]

Supplemental material is available for this article.

Received March 29, 2013; revised version accepted May 14, 2013.

Mammalian cell senescence is an active response to stresses that put cells at risk for neoplastic transformation, including DNA damage, oncogenic signals, dramatic chromatin changes, and critically shortened or dysfunctional telomeres (Campisi 2013). Accordingly, cell senescence limits carcinogenesis in a cell-autonomous fashion. Senescence may also have negative consequences, including contributing to carcinogenesis in a non-cell-autonomous manner and to age-related degenerative pathologies (Baker et al. 2011). Telomere shortening and uncapping are particularly important drivers of human cell senescence, as evidenced by the capacity of the telomerase enzyme to

Present addresses: 'Department of Pathology, Massachusetts General Hospital, Boston, MA 02114, USA. ${ }^{7}$ Faculty of Medicine, Ain Shams University, Cairo 11566, Egypt.

${ }^{8}$ Corresponding author

E-mail johnsonb@mail.med.upenn.edu

Article published online ahead of print. Article and publication date are online at http://www.genesdev.org/cgi/doi/10.1101/gad.218776.113. immortalize human cells and associations between dysfunctional telomeres and age-related diseases and progeroid syndromes (Armanios 2013). Senescent cells are characterized by persistent cell cycle arrest mediated by DNA damage checkpoint factors and also display profound changes in gene expression, chromatin organization, metabolism, and secretory behavior (Campisi 2013). The mechanisms underlying these changes are not well understood, but such knowledge promises to enhance our understanding of cancer and other age-related diseases.

In the budding yeast Saccharomyces cerevisiae, telomere length is maintained by telomerase, and thus yeast cells do not naturally senesce as a consequence of gradual telomere shortening. Telomere-driven senescence can be modeled in yeast by genetic inactivation of telomerase, leading eventually to critical telomere shortening and mitotic arrest (Lundblad and Szostak 1989). It is important to distinguish yeast senescence from yeast replicative aging and chronological aging. Replicative aging is 
measured by the number of daughters produced by a mother cell prior to her death, and chronological aging is measured by the time a yeast cell can survive under conditions of nutrient deprivation; however, neither of these aging models is driven by telomere shortening. Senescent yeast display several features remarkably similar to mammalian cells that have senesced due to telomere shortening. For example, both involve DNA damage responses (DDRs) and cell cycle arrest dependent on PI3-kinase-type kinases (IJpma and Greider 2003; Herbig et al. 2004). Both also involve activation of stress responses, inhibition of glycolysis, and down-regulation of mRNAs encoding the core histones (Nautiyal et al. 2002; Zwerschke et al. 2003; O'Sullivan et al. 2010). Critical telomere shortening in both settings causes loss of heterochromatic histone marks and subtelomeric gene silencing (Benetti et al. 2007; Kozak et al. 2010), and the telomere ends can fuse to one another (Blasco et al. 1997; Hackett et al. 2001; Capper et al. 2007). Furthermore, similar factors modulate the pace of senescence in both systems. For example, telomere-driven senescence in mammals is promoted by ATM, ATR, and EXO1 and is delayed by the WRN and BLM helicases, and in yeast, the orthologous proteins Tel1, Mec1, Exo1, and Sgs1 function similarly (Ritchie et al. 1999; Johnson et al. 2001; IJpma and Greider 2003; Herbig et al. 2004; Maringele and Lydall 2004; Schaetzlein et al. 2007; Abdallah et al. 2009). Thus, yeast telomerase mutants provide a valuable model for understanding several features of cell senescence.

We considered the possibility that telomere shortening might cause relocalization of normally telomere-bound proteins to new genomic loci and thus contribute to senescence, an idea long hypothesized but never demonstrated (Campisi 1997). A prime candidate for such a factor in S. cerevisiae is Rap1 (repressor activator protein 1). Rap1 binds directly to telomere repeat DNA in a sequence-specific fashion via two tandem Myb-type homeodomains linked by a short peptide (Konig et al. 1996). At telomeres, Rap1 contributes to capping and length regulation, localization to the nuclear periphery, and formation of heterochromatin (Klein et al. 1992; Kyrion et al. 1993; Palladino et al. 1993; Marcand et al. 1997; Pardo and Marcand 2005; Negrini et al. 2007; Vodenicharov et al. 2010). Rap1 mediates telomere silencing by recruiting the Sir protein complex (Moretti and Shore 2001). In contrast, at hundreds of genes, Rapl functions as a transcriptional activator via binding to upstream promoter regions and interacting with various coactivator proteins (Tornow et al. 1993; Schawalder et al. 2004; Zhao et al. 2006). These dual sets of Rap1 functions-at telomeres and at genomic loci-raise the possibility that if Rap1 were lost from shortened telomeres, it might expand its roles at extratelomeric loci. Several considerations support this idea. First, Rap 1 is an abundant protein ( 4000 molecules per haploid cell) (Buchman et al. 1988), and a significant fraction (at least 10\%-15\%) localizes to telomeres, which are visualized by fluorescence microscopy as prominent foci at the nuclear periphery that appear to be the primary sites of Rap1 localization (Klein et al. 1992; Gotta et al. 1996). Thus, the telomeric pool of Rap1 is large enough to have the potential for significant effects on redistribution. Second, many loci with consensus or near-consensus Rap1 target sequences are not bound by the protein in normal cells, raising the possibility that these sites might be bound under conditions that increase the available pool of Rap1 or increase site accessibility. Third, Rap1 relocalizes to some degree in the G2 phase of the cell cycle (Laroche et al. 2000) and under conditions of stress, including low glucose (Buck and Lieb 2006) and DNA damage by methyl methanesulfonate (MMS) (Tomar et al. 2008). Finally, senescence itself may be a Rap1relocalizing stress because fluorescence microscopy studies indicate that critical telomere shortening causes an apparent loss in intensity of telomere-associated Rap1 along with enhanced localization of Rap1 in numerous other nuclear regions (Palladino et al. 1993; Straatman and Louis 2007). However, the questions of whether Rap1 relocalizes to particular genomic targets at senescence and how such relocalization might impact gene expression and the rate of senescence have not been addressed.

Here we demonstrate that at senescence, Rap1 is lost from subtelomeric regions and localizes to upstream promoter regions of hundreds of new target genes. This redistribution of Rap1 depends on the Mec1 DDR kinase and plays direct roles in senescence-related gene expression. Remarkably, the genes encoding the core histones are among the new targets of Rap1, and Rapl contributes to a global decline in histone levels and also decreases nucleosome occupancy selectively at the promoters of genes that are up-regulated at senescence. Moreover, this Rap1-histone interplay impacts not only gene expression, but also the pace of senescence.

\section{Results}

\section{Rap1 targets new loci in senescent cells}

Chromatin immunoprecipitation (ChIP) using anti-Rap1 antibodies was performed in wild-type and senescent tlc1s cells, and the genomic distributions of enriched fragments were assessed using high-resolution tiling arrays (ChIP-chip) (Fig. 1A; Supplemental Fig. S1). Enrichment was calculated with respect to nonspecific IgG control ChIP, although essentially identical results were obtained when the comparison was made to input chromatin (data not shown). Using a conservative MAT (model-based analysis of tiling arrays) cutoff of $10^{-5}$ (see the Materials and Methods), 798 Rap1 target genes were identified in wild-type cells. These targets were highly similar to those identified previously (Supplemental Fig. S2, $P=2.5 \times 10^{-123}$ ) (Harbison et al. 2004). At senescence, three major types of changes in Rap1 localization were apparent. First, there is increased enrichment at many sites already targeted by Rap1 in wild-type cells (Fig. 1A; Supplemental Fig. S1). Second, and more strikingly, there are many new Rap1 target peaks (Fig. 1A; Supplemental Fig. S1). Third, Rap1 occupancy declines at subtelomeres (Figs. 1B, 7B [below]; Supplemental Fig. S3). These changes do not reflect alterations in overall Rap1 levels, which remain nearly constant per cell (Figs. 1C 
Platt et al.

A.

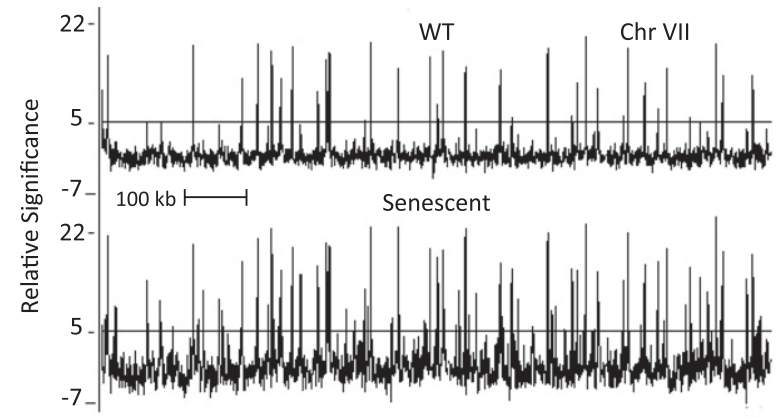

B.
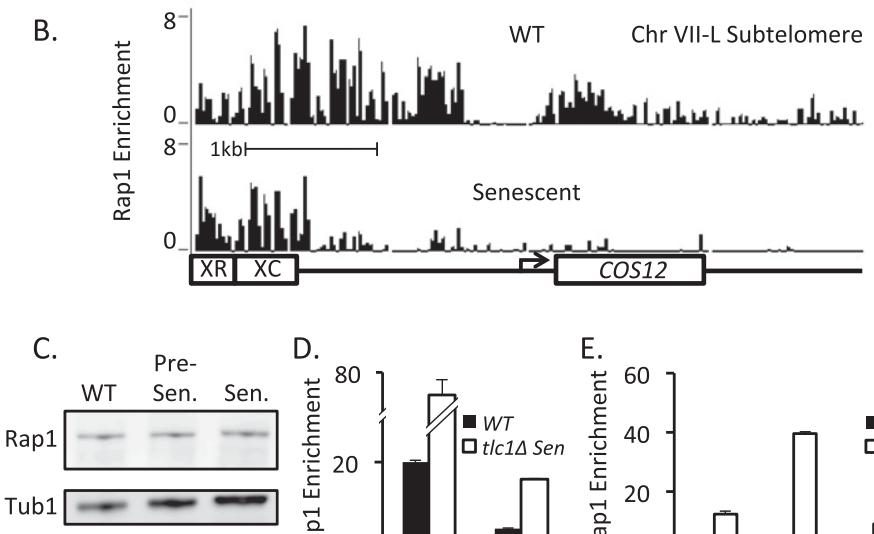

D.

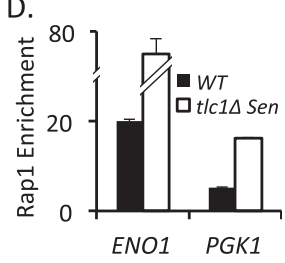

E.

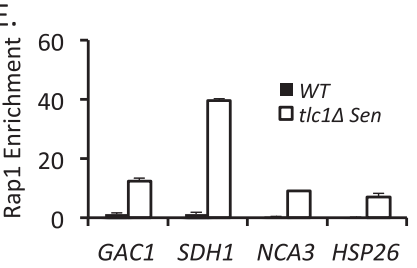

F.

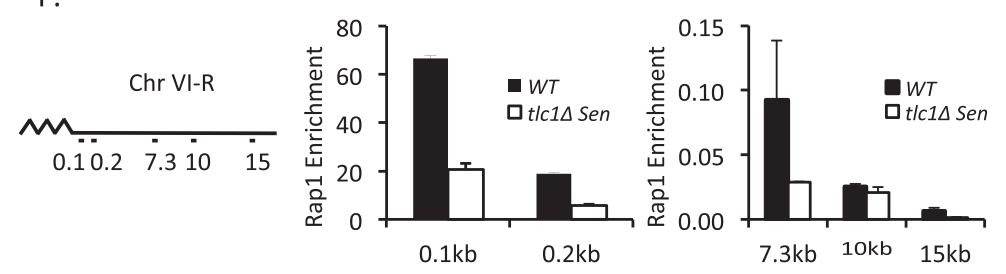

Figure 1. Rap1 leaves subtelomeres and redistributes to new genomic loci at senescence. $(A)$ Chromosomal distribution of Rapl in wild-type and senescent cells. Rap1 ChIP tiling array data, normalized to control rabbit IgG ChIP data, are shown for chromosome VII (see Supplemental Fig. S1 for all chromosomes). Data are plotted by relative significance using the MAT algorithm $\left[-\log _{10}(P\right.$-value $\left.)\right]$. Senescent cells were obtained five PDs prior to the nadir in growth rate to avoid contributions by survivors of senescence. $(B)$ Rap1 leaves subtelomeres at senescence. Rap1 ChIP tiling array data are shown for subtelomere VII-L. Data are plotted as the $\log _{2}$ ratio of the Rap1 and control rabbit IgG ChIP signal intensities. (C) Rap1 protein levels do not change substantially at senescence. Rap1 and tubulin immunoblots of whole-cell extracts from equal numbers of cells from wild-type and $t 1 c 1 \Delta$ cultures at $\sim 30$ PDs (presenescent) and $\sim 70$ PDs (senescent). Note that tubulin levels per cell increase at senescence, consistent with increased cell volume (Nautiyal et al. 2002). (D-F) Rap1 ChIP-qPCR analyses confirming that at senescence, Rapl displays enhanced enrichment at sites naturally targeted in wild-type (WT) cells $(D)$ and at NRTS $(E)$, whereas Rapl occupancy decreases at subtelomeres $(F)$. Rapl enrichment is the ratio of the Rapl level at each targeted locus compared with $A C T 1$, normalized to nonspecific IgG and input controls. The locations of qPCR probes along subtelomere VI-R are shown. All qPCR data are means $(N=3)$, and similar results were obtained in two other experiments using independent biological replicates. [which compares equal cell numbers], 7D [below]; data not shown). All three types of changes were confirmed via ChIP and quantitative PCR (ChIP-qPCR) against multiple targets (Fig. 1D-F, Rap1 ChIP enrichment was in comparison with $A C T 1$ and was normalized to $\operatorname{IgG}$ and input controls).

We found that Rap 1 localizes to 491 new target genes at senescence, and we refer to these as NRTS (new Rap1 targets at senescence) (Fig. 2A). Similar to Rap1 targets in normal cells, NRTS were localized primarily in upstream promoter regions (Fig. 2B,C; Supplemental Fig. S4). We searched for enriched sequence motifs within the NRTS promoters using HOMER, a de novo motif discovery program (Heinz et al. 2010). Whereas the previously defined Rap1 consensus CACCCA(A/C)ACA (Lieb et al. 2001) was the most significant motif identified in the wild-type targets (798 genes), it was not found in the NRTS target set (Fig. 2D). Instead, the most significant NRTS motif $\left(P=10^{-12}\right)$ was TTTTTTGCG(C/G), which may have weak nucleosome-destabilizing activity (Segal and Widom 2009; Wu and Li 2010). Consistent with this possibility, at senescence, Rap1 preferentially targets regions of the genome where histones have been found to have high turnover under normal conditions $(P$-value $=$ $1.4 \times 10^{-84}$ ) (Supplemental Table S1). Even though NRTS are not enriched for consensus Rap1-binding sites, they are enriched for suboptimal Rap1-binding sites (Supplemental Table S2A,B). The tandem Myb domains of Rap1 each binds hemisites within consensus targets, and the peptide linking the Myb domains binds a 3-nucleotide (nt) spacer linking the hemisites (Konig et al. 1996). Rap1 can also bind with significant affinity (reduced fivefold to 10-fold from its optimal $10^{-11} \mathrm{M} \mathrm{Kd}$ ) to a single hemisite paired with a linker sequence (cf. Supplemental Table S2A; Del Vescovo et al. 2004). Such hemisite-linker sites were enriched within NRTS $\left(P=2.7 \times 10^{-4}\right.$ for the presence of at least one such site) (Supplemental Table S2). Furthermore, in vitro Rap1-binding data (Mukherjee et al. 2004) indicate that Rap1 binds NRTS promoters with an affinity lower than for natural Rap1 targets but substantially higher than non-Rap1 targets (Fig. 2E). Thus, DNA binding by Rap1 may contribute to NRTS occupancy. Overall, it appears that the forces dictating Rap1 occupancy at the NRTS versus normal targets differ 
A.

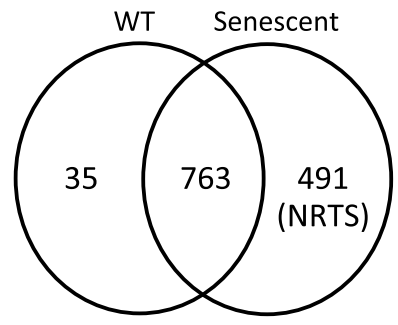

B.
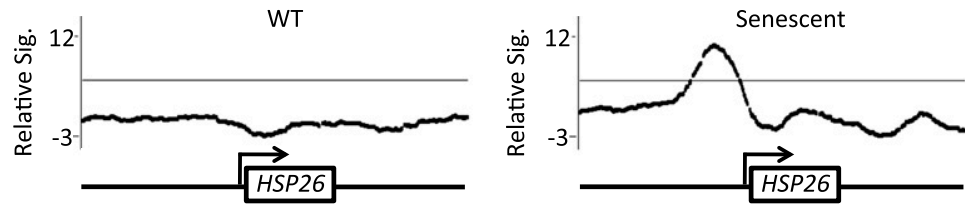

C.
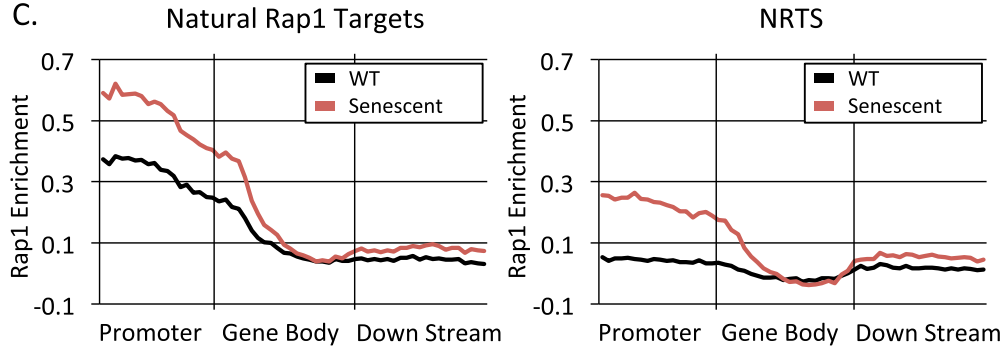

D.

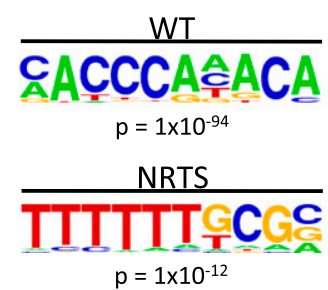

E.

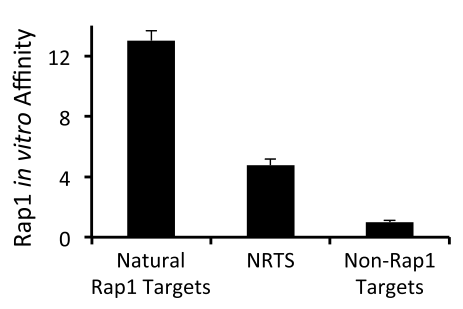

Figure 2. NRTS. (A) Venn diagram comparing Rap1 target genes in wild-type and senescent cells. The 35 targets lost at senescence are largely from subtelomeric regions (Supplemental Fig. S3B). (B) HSP26 is an example of a NRTS. Data are plotted as in Figure 1A. (C) Rap1 occupancy at senescence increases preferentially at the promoters of both sites naturally targeted in wild-type (WT) cells (natural Rap1 targets, $n=763)$ and NRTS $(n=491)$. Data are plotted as the average ChIP intensities $\left[\log _{2}(\mathrm{Rap} 1 \mathrm{ChIP} / \mathrm{rabbit}\right.$ IgG ChIP)] for the genes in each category within and flanking each gene. (Promoter) The 500-base-pair (bp) region upstream of the ORF; (gene body) the ORF; (downstream) the 500-bp region downstream from the ORF. (D) NRTS are not enriched for the consensus Rapl-binding sequence. The most significant motif identified using HOMER among wild-type target genes is the Rap1-binding consensus, and the most significant motif among NRTS is shown. $(E)$ Rap1 binds sequences in NRTS promoters. Rap1 in vitro affinity was measured by protein-binding microarrays (Mukherjee et al. 2004). due to changes in Rap1, its cofactors, or the chromatin structure of the target sites themselves.

\section{NRTS are preferentially up-regulated by Rap1 at senescence}

In wild-type cells, Rap1 activates transcription at most of its target genes but also contributes to transcriptional silencing at subtelomeres and the silent mating loci. To address whether Rap1 affects gene expression of the NRTS, we first examined microarray-based mRNA expression analyses for senescent $t$ lc1 $1 \Delta$ mutants (Nautiyal et al. 2002). Remarkably, the NRTS preferentially overlap the set of genes that are up-regulated at senescence $(P=$ $1.9 \times 10^{-5}$ ) (Fig. 3A). Furthermore, Rap1 specifically targets some of the most highly up-regulated genes at senescence; e.g., HSP26, NCA3, and GAC1 (Fig. 2B; Supplemental Fig. S4A). In contrast, there is no enrichment for NRTS within the set of genes down-regulated at senescence $(P=1)$. We note also that the majority of NRTS are not regulated significantly at senescence, and so Rap1 binding is apparently not sufficient to confer regulation in all cases. In other words, although some NRTS are up-regulated, others are down-regulated, and most are not regulated at senescence; overall, the set of NRTS genes shows a statistical tendency to be up-regulated.

To test whether Rap1 activates expression of the NRTS that are up-regulated at senescence, we elevated Rap1 levels in wild-type cells twofold by introducing a singlecopy plasmid with RAP1 expression driven by the NOP1 promoter (NOP1p-RAP1) (Fig. 3B; Supplemental Fig. S5) and then measured changes in Rap1 occupancy and gene expression at NRTS. Although high levels of Rap1 are toxic (Freeman et al. 1995), the twofold increase in Rap1 inhibited cell growth only slightly (Supplemental Fig. S5C). In comparison with the nontargeted ACT1 locus, Rap1 overexpression caused significant elevations in Rap1 binding at the upstream promoter regions of senescenceup-regulated NRTS (Fig. 3C, vs. ACT1) and in the levels of mRNA from these genes (Fig. 3D) in all cases tested. Control experiments confirmed that Rap1 does not regulate the ACT1 locus (Supplemental Fig. S5D,E). Therefore, increasing the level of Rap1 is sufficient to mimic 
Platt et al.

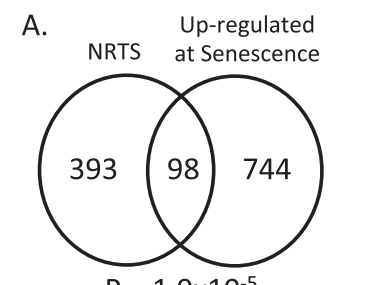

C.
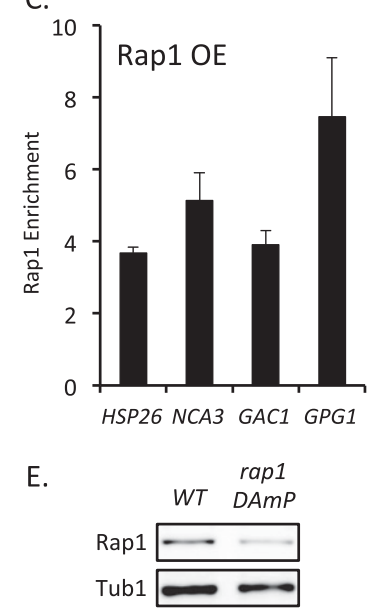

G.

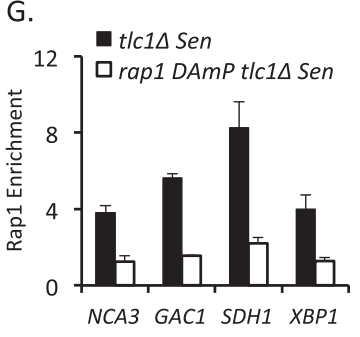

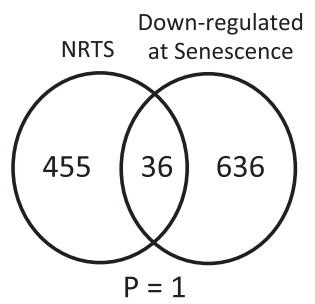

B.

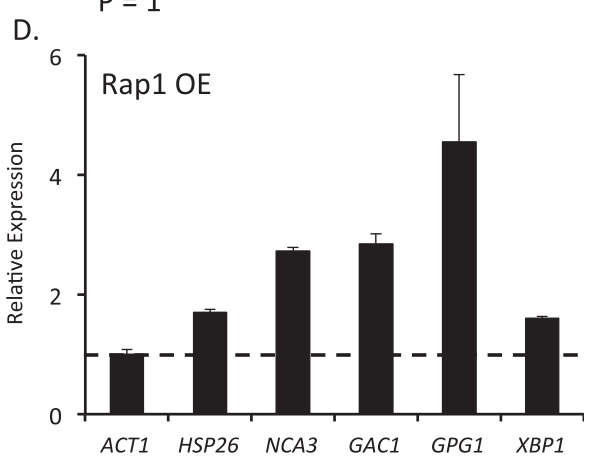

$\mathrm{F}$.

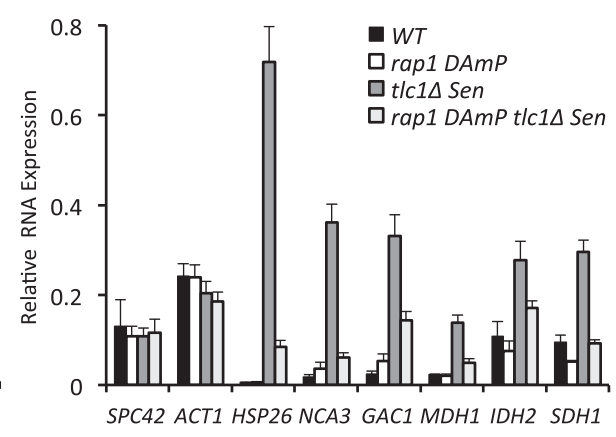

Figure 3. NRTS are preferentially up-regulated by Rap1 at senescence. (A) Venn diagram comparing NRTS with genes that are differentially expressed $(\geq 1.5$-fold) at senescence (among 6178 genes total). $(B-D)$ A twofold elevation in Rap1 levels is sufficient to mimic effects of senescence at up-regulated NRTS in wild-type (WT) cells. (B) Immunoblots of TCA extracts from equal numbers of cells carrying the NOP1p-RAP1 plasmid (Rap1 OE) or the vector control (Ctrl). (C) Rap1 levels at the promoters of up-regulated NRTS. Rap1 enrichment is the ratio of Rap1 levels measured by qPCR in NOP1p-RAP1 versus vector control cells normalized to ACT1. $(D)$ Up-regulated NRTS are activated by Rap1 overexpression. Data are RNA levels in Rap1 OE cells relative to control cells and normalized to ACT1 transcripts. $(E-G)$ Rap1 contributes to up-regulation of NRTS at senescence. (E) Rap1 levels are reduced in rap1 $D A m P$ cells. Immunoblots of TCA extracts from equal numbers of wild-type and rap1 DAmP cells. (F) Rap1 contributes to activation at senescence of up-regulated NRTS. mRNA levels were measured by qPCR in wildtype $(n=2)$, rap1 DAmP $(n=2)$, and senescent (tlc1s Sen, $n=4$; rap1 DAmP t1c1s Sen, $n=4$ ) cultures. (G) Reduced Rap1 levels blunt Rap1 occupancy at the upstream promoters of NRTS at senescence. Data are plotted as fold change in Rap1 enrichment in senescent cells relative to wild-type cells and normalized to occupancy at the ACT1 locus, as measured by qPCR. All qPCR data are means ( $N=3$, except as noted), and similar results were obtained in two other experiments using independent biological replicates. the effects of senescence on up-regulated NRTS. We confirmed the importance of Rap1 in the up-regulation of these NRTS by decreasing the levels of Rap1 at senescence. Because RAP1 is essential, we could not test the effects of deleting RAP1 entirely but were able to decrease Rap1 levels $\sim 40 \%$ using the hypomorphic rap1 $D A m P$ (decreased abundance by mRNA perturbation) allele (Fig. 3E; Supplemental Fig. S5F; Breslow et al. 2008). rap1 DAmP blunted the up-regulation in NRTS mRNA levels at senescence and, in contrast, did not affect mRNA levels from the nontargeted ACT1 and SPC42 control loci (Fig. 3F); control ChIP experiments confirmed that the allele also reduced Rap1 levels at these NRTS at senescence (Fig. 3G, vs. ACT1). Therefore, for NRTS that are activated at senescence, Rap1 relocalization to these loci apparently contributes to their up-regulation.

Because senescence results in a G2/M cell cycle arrest, we wondered whether altered expression of NRTS might be a secondary effect of the arrest. Comparison of the NRTS genes that are senescence-regulated (Nautiyal et al. 2002) with those that are mitotic arrest-regulated (Spellman et al. 1998) revealed a nonsignificant overlap between up-regulated data sets $(P=1$, Supplemental
Fig. S6A $)$ and down-regulated data sets $(P=0.65$, Supplemental Fig. S6B). In addition, qPCR analyses showed that expression of senescence-up-regulated NRTS genes either did not change or was diminished with nocodazolemediated arrest (Supplemental Fig. S6C). These findings suggest that the Rap1-dependent regulation of NRTS is largely independent of G2/M arrest per se.

\section{Rap1 targets and represses the core histone genes at senescence}

Gene ontology (GO) analysis of the NRTS revealed enrichment for genes involved in metabolism, stress responses, and aspects of DDRs (Supplemental Table S3). These broadly reflect the functional categories of genes with altered expression noted previously for senescent tlc1s mutants (Nautiyal et al. 2002), indicating that Rap1 does not target a narrow functional subset of senescenceregulated genes. However, we were surprised to find that the second most significant GO category for the NRTS was the nuclear nucleosome $\left(P=2.2 \times 10^{-4}\right)$, including all of the genes encoding the core histone proteins H2A, $\mathrm{H} 2 \mathrm{~B}, \mathrm{H} 3$, and H4. Indeed, direct inspection of ChIP-chip data for the loci encoding these proteins-HTA1-HTB1, 
HTA2-HTB2, HHT1-HHF1, and HHT2-HHF2-revealed significant Rap1 binding in senescent cells (Fig. 4A). HTZ1 (encoding the only $S$. cerevisiae H2A variant histone) was also strongly targeted by Rap1 at senescence, whereas HHO1 (encoding the H1-like protein) was weakly targeted, and CSE4 (encoding the centromerespecific H3 variant histone) was not (Supplemental Fig. S7A). These findings were confirmed using Rap1
A.
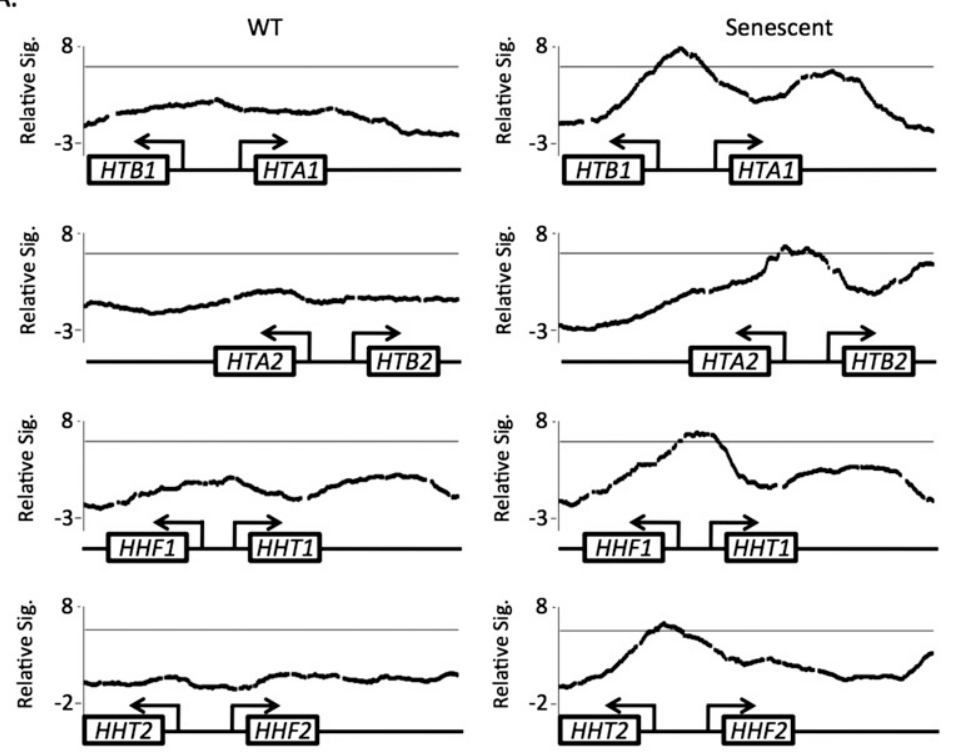

C.

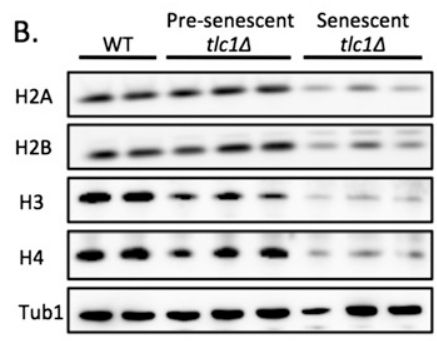

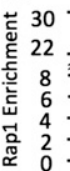

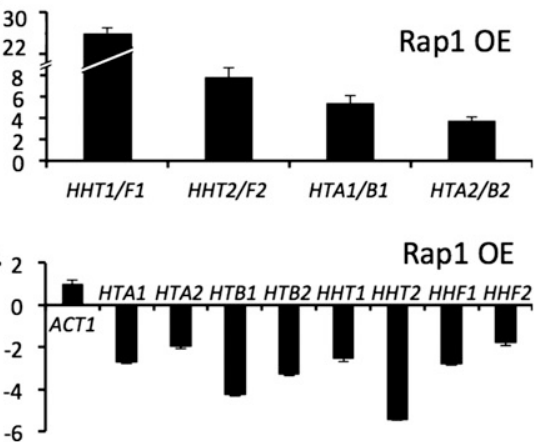

E.

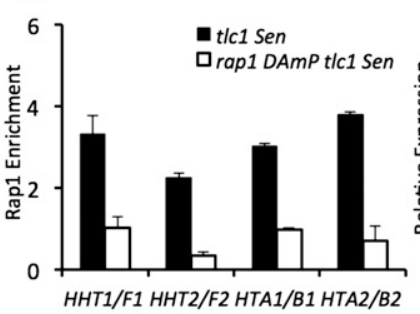

F.

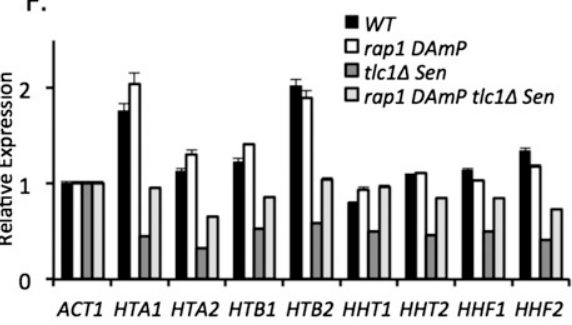

G.

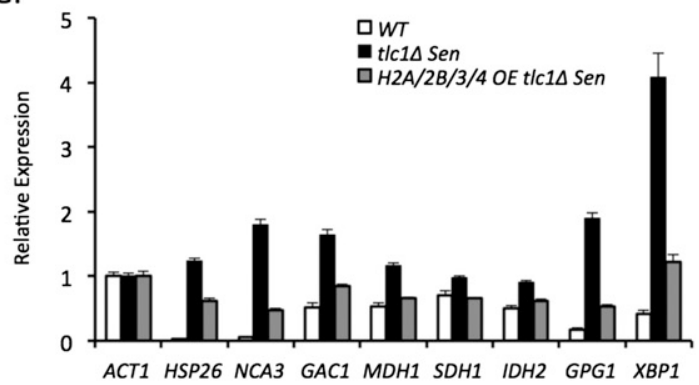

Figure 4. Rap1 targets and represses core histone gene expression at senescence. $(A)$ Rapl binds all core histone promoters at senescence. Data are plotted as in Figure 1A. (B) Histone protein levels decrease at senescence. Immunoblots of whole-cell extracts from the indicated wild-type $(n=2)$ and tlc1s cultures at $\sim 30$ PDs (presenescent, $n=3$ ) and $\sim 70$ PDs (senescent, $n=3$ ). Lanes were loaded by equal protein and stained with anti-H2A, anti-H2B, anti-H3, anti-H4, or anti-tubulin antibodies. $(C, D)$ Increased levels of Rap1 are sufficient to repress histone gene expression. (C) Rapl occupancy at core histone promoters is increased in wild-type $(\mathrm{WT})$ cells carrying the NOP1p-RAP1 plasmid. Data are plotted as in Figure 3C. $(D)$ Increased Rap1 levels blunt histone gene expression. qPCR data are fold changes in mRNA expression in nocodazolearrested wild-type cells carrying the NOP1p-RAP1 plasmid $(n=3)$ relative to arrested vector control strains $(n=3)$, normalized to $A C T 1$ transcripts. $(E, F)$ Rap1 contributes to core histone gene repression at senescence. (E) Reduced levels of Rap1 in rap1 $D A m P$ mutants blunt Rapl occupancy at histone promoters at senescence. Data are plotted as in Figure 3G. $(F)$ Repression of core histone genes depends on Rap1. mRNA levels were measured by qPCR normalized to ACT1 transcripts using RNA from wild-type $(n=2)$, rap1 $D A m P(n=2)$, senescent (tlc1s Sen, $n=4)$, and senescent rap1 DAmP (rap1 $D A m P$ tlc1s Sen, $n=4)$ cultures. (G) Histone overexpression blunts up-regulation of NRTS at senescence. mRNA levels were measured by qPCR in wild-type $(n=2)$, senescent tlc1s $(n=4)$, and senescent $\mathrm{H} 2 \mathrm{~A} / \mathrm{H} 2 \mathrm{~B} / \mathrm{H} 3 / \mathrm{H} 4-$ overexpressing tlc1s $(n=4)$ cultures. 
ChIP-qPCR (Supplemental Fig. S7B). Diminished expression of the core histone loci at senescence was noted previously (Nautiyal et al. 2002), but these loci have never been identified as Rap1 targets. In keeping with these observations, we found that the levels of histone proteins $\mathrm{H} 2 \mathrm{~A}, \mathrm{H} 2 \mathrm{~B}, \mathrm{H} 3$, and $\mathrm{H} 4$ were significantly reduced at senescence (Fig. 4B; Supplemental Fig. S7C,D). The decline in histone levels was not a simple consequence of G2/M arrest because, except for small reductions in $\mathrm{H} 3$ and $\mathrm{H} 4$, histone levels remained largely steady following treatment of wild-type cells with nocodazole (Supplemental Fig. S7E).

Even though NRTS are not enriched overall for genes that are down-regulated at senescence, it is still possible that Rap1 contributes to the senescence-related downregulation of histone genes. We found that Rap1 overexpressed by twofold (via plasmid-based NOP1p-RAP1) in wild-type cells led to elevated Rap1 binding at all histone promoters (Fig. 4C) along with repression of histone gene expression and protein levels in cells that had been arrested with nocodazole (Fig. 4D; Supplemental Fig. S7F). This Rap1-dependent repression was not observed unless cells were arrested in this fashion (data not shown), consistent with the requirement for normal histone levels to support cell cycle progression and with the natural arrest of senescent cells in G2/M. Moreover, reduction in Rap1 levels via rap1 DAmP at senescence reduced Rap1 occupancy at the histone loci (Fig. 4E) and blunted histone gene down-regulation (Fig. 4F). Therefore, Rap1 binds and inhibits the expression of the core histone genes at senescence.

Rap1 requires the Sir2/3/4 protein complex to silence telomeres and the silent mating loci (Strahl-Bolsinger et al. 1997), and furthermore, the Sir complex has been found to relocalize from telomeres to genomic loci under various stresses (Martin et al. 1999). We therefore asked whether repression of the histone loci might depend on the Sir complex. However, repression proved to be Sirindependent, as deletion of SIR2, SIR3, or SIR4 did not affect down-regulation of the core histone loci in senescent cells (Supplemental Fig. S8).

\section{Histone losses contribute to altered gene expression at senescence and connect to reciprocal occupancy of Rap1 and histones at NRTS}

Because histone RNA and protein levels are dramatically down-regulated at senescence, we wondered whether these processes might contribute to selective gene expression changes at senescence. To address this question, we first compared genes that change in expression following acute histone H4 depletion (Wyrick et al. 1999) with (1) genes that are differentially expressed at senescence (Nautiyal et al. 2002) and (2) genes that are differentially expressed at senescence and are also NRTS. These comparisons revealed a significant overlap in all cases (up-regulated with $\mathrm{H} 4$ depletion and senescence: $P=4.5 \times$ $10^{-18}$; down-regulated with $\mathrm{H} 4$ depletion and senescence: $P=1.7 \times 10^{-49}$; the same up-regulated and downregulated data sets restricted to NRTS: $P=3.1 \times 10^{-4}$ and $P=3.5 \times 10^{-7}$, respectively) (Supplemental Table S4A,B). The reduced significance of the NRTS subset is a consequence of the smaller number of loci involved. In fact, the fraction of genes up-regulated/down-regulated at senescence that are also up-regulated/down-regulated with $\mathrm{H} 4$ depletion is greater when restricted to the NRTS (29\% and $42 \%$, for up-regulated and down-regulated loci, respectively) than for genes overall $(20 \%$ and $34 \%$, for upregulated and down-regulated loci, respectively). In addition, we discovered that genes up-regulated at senescence tend to display rapid histone turnover in wild-type cells (Supplemental Table S5), indicating that they naturally contain low-stability nucleosomes, and, as noted above (Supplemental Table S1), such high-turnover regions are preferentially targeted by Rap1 at senescence. Finally, we found that overexpression of the four core histone proteins in senescent cells (via GAL1-10-driven expression of HTA1-HTB1 and HHT2-HHF2) (Feser et al. 2010) blunts the activation of NRTS at senescence (Fig. 4G). Therefore, histone loss appears to be an important contributor to changes in gene expression at senescence, particularly those governed by redistribution of Rap1 to new target genes.

Rap1 and nucleosome occupancy have been found to correlate inversely at many genomic loci, which might reflect an ability of Rap1 to compete directly with nucleosomes for some DNA sites or might instead be an indirect consequence of nucleosome losses associated with transcriptional activation by Rap1 at target genes (Yu and Morse 1999; Koerber et al. 2009; Ganapathi et al. 2011; Rhee and Pugh 2011; Lickwar et al. 2012). ChIP-qPCR analyses for Rap1 and histone $\mathrm{H} 3$ demonstrated reciprocal changes for the proteins at NRTS that are activated at senescence, in comparison with the ACT1 locus, which is not targeted by RAP1 (Fig. 5A). Thus, histones are not lost uniformly from chromatin at senescence, and loss is more pronounced at activated NRTS. Rap1 is required for these losses because senescent cells containing the rap1-DAmP allele accumulated reduced levels of Rap1 at these loci, and the loss of histone $\mathrm{H} 3$ from these loci was blunted or blocked completely (Fig. 5B). In addition, and consistent with a reciprocal relationship between Rap1 and nucleosome occupancy, overexpression of the four core histone proteins in senescent cells similarly inhibited accumulation of Rap1 and the loss of histone $\mathrm{H} 3$ at these activated NRTS (Fig. 5C). To rule out the possibility that histone losses at these loci was an indirect consequence of decreased histone levels overall, we performed a time course of Rap1 overexpression in wild-type cells and demonstrated that histone $\mathrm{H} 3$ is lost from activated NRTS with more rapid kinetics than any reduction in overall histone protein levels (Supplemental Fig. S9).

Because the core histone loci are a class of NRTS that are repressed by Rap1 at senescence, we explored how senescence affects the relationships between Rap1 and histones at the promoters of these loci. Although ChIPqPCR tests confirmed that Rap1 accumulates at the upstream promoter regions of the histone genes at senescence, histone $\mathrm{H} 3$ was actually retained (in contrast to $\mathrm{H} 3$ losses at the activated NRTS) (Fig. 5D). Furthermore, 
A.

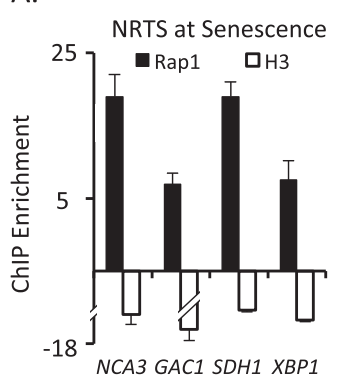

B.

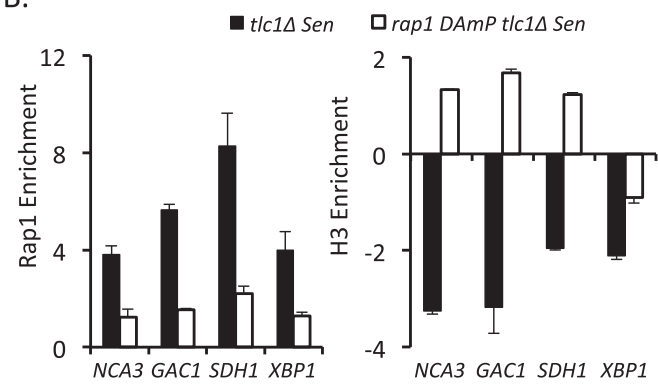

Figure 5. A reciprocal relationship exists between Rap1 and histone occupancy at activated NRTS. Rap1 or H3 ChIP-qPCR data are plotted as fold changes in Rap1 and $\mathrm{H} 3$ enrichment in senescent cells relative to wild-type (WT) cells, normalized to ACT1. (A) Histones are preferentially lost at activated NRTS. (B) Rapl contributes to histone loss at activated NRTS because such losses are reduced in rap1 DAmP cells at senescence. $(C)$ Overexpression of the core histone loci blunts elevated Rapl occupancy and histone loss at activated NRTS. $(D)$ Histones are not preferentially lost at core histone promoters at senescence. (E) Rap1 does not significantly affect histone occupancy at the core histone promoters at senescence. All qPCR data are means $(N=3)$; similar results were obtained in three other experiments using independent biological replicates and also when data were normalized to RSP5 (a non-Rap1 targeted locus) instead of ACT1.

although senescent rap1-DAmP cells accumulated reduced levels of Rap1 at the histone loci, H3 actually became slightly enriched in comparison with senescent cells with normal levels of Rap1 (Fig. 5E) even though histone gene repression at senescence is alleviated (i.e., derepressed) by rap1-DAmP (cf. Fig. 4F). Therefore, Rap1dependent repression of the histone loci at senescence is associated with retention of histones in histone gene promoter regions but also must involve additional Rap1dependent repressive mechanisms.

\section{Rap1 drives the rate of senescence}

Although Rapl targets new loci and drives gene expression changes in senescent cells, it did not necessarily follow that such events would impact the rate of senescence. To test this possibility, we compared senescence in cells with wild-type to reduced levels of Rap1 (i.e., tlc1s vs. rap1-DAmP tlc1s). As in all of our comparisons of senescence in cells of different genotypes, we performed this experiment with the haploid progeny derived from a single $T L C 1 /$ tlc1 1 diploid that was also heterozygous for the allele to be tested (i.e., RAP1/rap1-DAmP in this case); thus, the different haploids inherit telomeres of similar lengths, enabling fair comparisons between genotypes. Remarkably, the rap1-DAmP tlc1s cells senesced significantly more slowly than the control tlc1s cells (Fig. 6A; $P=0.0012$ ). This is not an effect of early activation of the homologous recombination (HR)-dependent survivor pathway of telomere maintenance (Lundblad and Blackburn 1993) because the rap1-DAmP tlc1s mutants reached their growth nadir and formed survivors after more, rather than fewer, population doublings (PDs) ( $\sim 85$ vs. 70 PDs). The delayed senescence is a somewhat surprising result because Rap1 naturally contributes to telomere capping (Pardo and Marcand 2005; Negrini et al. 2007; Vodenicharov et al. 2010), and thus a reduction in Rap1 levels might be expected to exacerbate telomere dysfunction. We infer that the Rapl proteins bound tightly to telomere repeat DNA (Kd $\sim 10^{-11} \mathrm{M}$ ) (Vignais et al. 1990) are unaffected by the small reduction in Rap1 levels, whereas it is clear that Rapl binding at NRTS loci, which lack canonical Rapl-binding sites, is diminished (Fig. 3G). This inference is supported by our finding that there are normal levels of Rap1 at telomere repeats in the DAmP strain, as indicated by ChIP /Supplemental 
Platt et al.

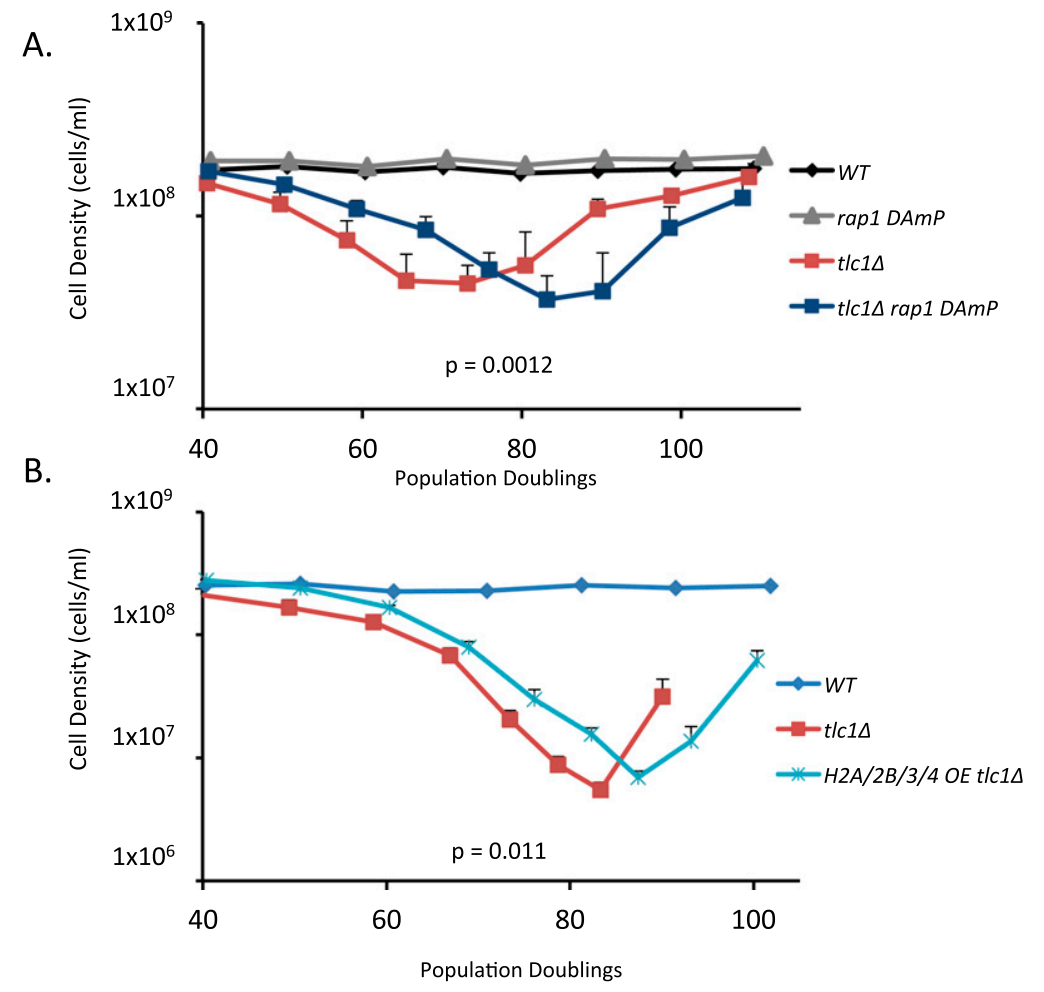

Figure 6. Reduced Rap1 levels or increased histone levels delay senescence. (A) Rap1 drives senescence. Senescence assay of wild-type (WT) $(n=2)$, rap1 $D A m P(n=2)$, tlc1s $(n=4)$, and rap1 DAmP tlc1s $(n=4)$ cultures. $P=0.0012$ for delayed senescence by rap1 DAmP. (B) Increased histone levels delay senescence. Senescence assay comparing wild-type $(n=1), t 1 c 1 \Delta(n=7)$, and tlc1s cells overexpressing core histone proteins $(H 2 A / 2 B / 3 / 4$ tlc $1 \Delta ; n=5)$. $P=0.011$ for delayed senescence by histone overexpression.

Fig. S5G,H) and the capacity of the DAmP allele to maintain normal telomere length and prevent end fusions (Ungar et al. 2009; Lescasse et al. 2013). Overall, our findings indicate that Rap1 drives not only the gene expression phenotype, but also the pace of senescence.

\section{Histone overexpression delays senescence}

We wondered whether the antagonistic relationships between Rap1 and histones also apply to the rate of senescence. We compared cells with normal histone loci with those also overexpressing the four core histones (using histone genes under GAL1-10 control, as above) and found that histone overexpression delays senescence (Fig. 6B). Therefore, the pace of senescence is apparently propelled by the histone losses that accompany it, and the prosenescence role of Rap1 may be explained by its capacity to inhibit histone expression and function.

\section{Rap1 relocalization and function at senescence depends on MEC1}

The loss of Rap1-binding sites caused by telomere shortening might contribute to its relocalization in senescent cells. However, critically shortened telomeres in senescent cells activate a DDR, and Rap1 has previously been found to localize to the RNR3 locus in cells exposed to MMS in a fashion that depends on the DDR checkpoint kinases Mec1 and Dun1 (Tomar et al. 2008), raising the possibility that the DDR contributes to Rap1 relocalization at senescence. We therefore investigated what DDR factors are involved in Rap1 functions at senescence, including the PI3-type kinases Mec1 and Tell and the Dun1 kinase. Dun1 acts downstream from the Rad53 kinase, which itself is partially responsible for mediating signaling from Mec1 and Tell (Putnam et al. 2009). Tel1 localizes to short telomeres (Sabourin et al. 2007) and can contribute to the pace of senescence (Ritchie et al. 1999; Abdallah et al. 2009), but the G2/M arrest at senescence depends on Mec1 and is independent of Tell and Rad53 (Enomoto et al. 2002; IJpma and Greider 2003). Therefore, one or more of these DDR factors might affect the action of Rap1 at senescence.

We examined the expression of up-regulated NRTS at senescence by qPCR and found that for all eight loci examined, deletion of $M E C 1$ substantially blunted their up-regulation, but deletion of TEL1 or DUN1 had no effect (Fig. 7A; Supplemental Fig. S10). In addition, MEC1 deletion partially or completely rescued histone downregulation at senescence (Fig. 7A). In keeping with these results, Rap1 ChIP-qPCR demonstrated that MEC1 is required at senescence for full loss of Rapl at subtelomeres (Fig. 7B) and for enrichment at NRTS (Fig. 7C). Our findings indicate that Mec1 is necessary to remove Rap1 from subtelomeres and deposit it at its novel target sites at senescence. The dependence on Mec1, but not Tell and Dun1, correlates with the requirements for G2/M arrest at senescence. In addition, TCA-extracted Rap1 displayed reduced-mobility forms at senescence, which are also dependent on MEC1 (Fig. 7D). Therefore, although additional studies will be required to understand the nature and functional significance of these apparent Rap1 modifications, these findings raise the possibility that post- 
A.
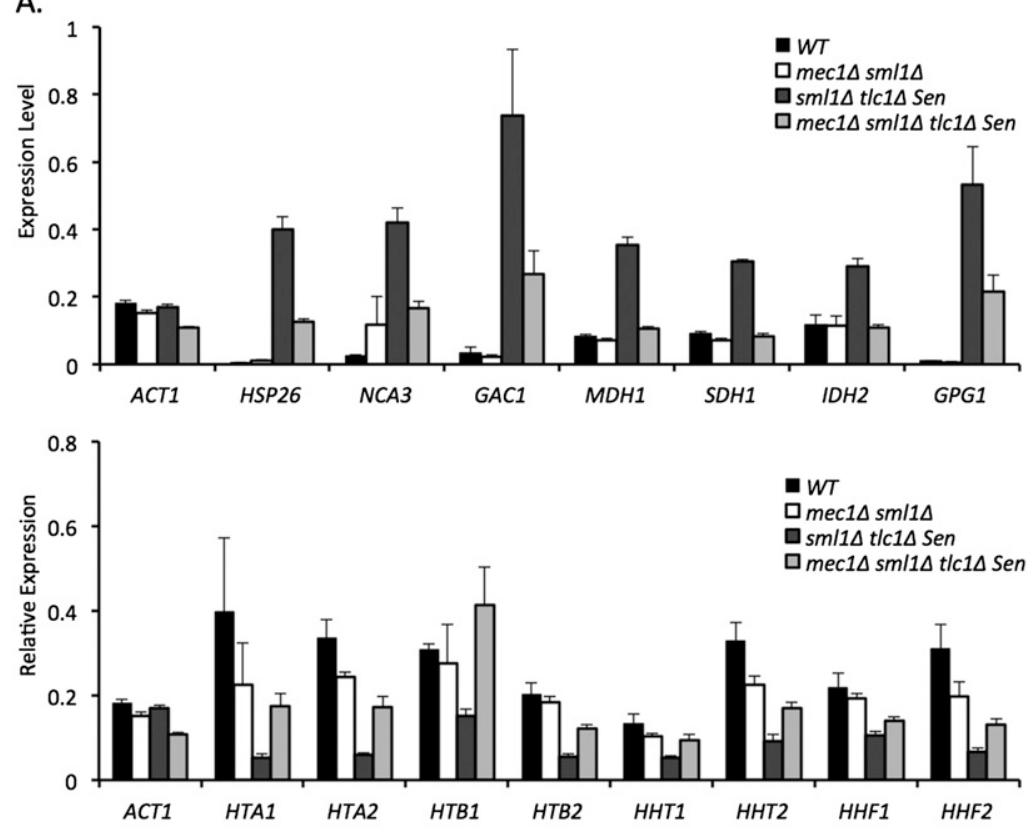

B.

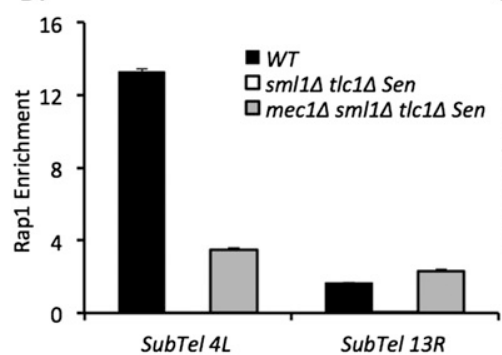

C.

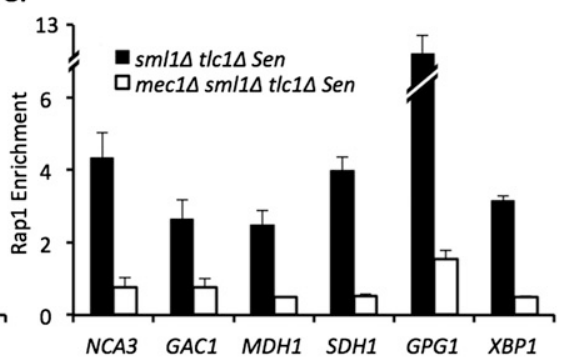

Figure 7. Rap1 relocalization and function at senescence requires MEC1. (A) Activation of NRTS and repression of histones at senescence depend on $M E C 1$. qPCR measurements of mRNA from wild-type (WT) $(n=2)$, mec1s sml1s $(n=2)$, senescent sml1s tlc1s $(n=4)$, and senescent

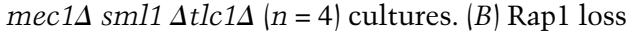
from subtelomeres depends on MEC1. ChIP data are plotted as in Figure 1F. Subtelomere 4L and 13R qPCR amplicons are, respectively, 0.11 and $0.2 \mathrm{~kb}$ away from the base of the telomeric repeats. $(C)$ Rapl localization to activated NRTS depends on MEC1. ChIP data are plotted as in Figure 3G. $(D)$ Slower-mobility species of Rap1 present at senescence depend on MEC1. Immunoblots of TCA extracts, loaded by equal cell number and stained with anti-Rap1 or anti-tubulin antibodies. For all experiments, senescent cultures were harvested five PDs prior to the growth nadir, which for sml1s tlc1s was $\sim 70$ PDs and for mec1s sml1s tlc1s was $\sim 80$ PDs.

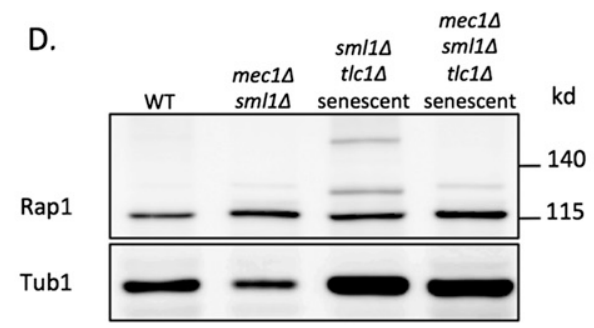

translational modification of Rap1 is involved in its relocalization.

\section{Discussion}

Our experimental findings show that Rapl targets the upstream promoter regions of hundreds of novel targets at senescence (the NRTS) and plays important roles in the regulation of these targets. NRTS tend to be up-regulated at senescence overall, but some NRTS are down-regulated, most notably the genes encoding the core histone proteins. This was a surprising finding because, although Rap 1 normally targets at least $5 \%$ of all genes, it has never before been observed at the histone genes. Consis- tent with the down-regulation of histone transcripts in senescent yeast (Nautiyal et al. 2002), we show for the first time that histone protein levels also decline significantly. Histone losses appear to be critical mediators of senescence because the gene expression changes in senescent cells are remarkably similar to those following acute depletion of histone $\mathrm{H} 4$ and because senescence can be delayed by overexpression of the core histone genes. Histone losses have also been observed recently in other aging-related settings, including replicatively aged yeast mother cells and senescent cultured human fibroblasts, suggesting that histone losses may be a conserved feature of aging and senescence (Feser et al. 2010; O'Sullivan et al. 2010). Importantly, the mechanisms underlying histone 
losses in these other settings are not known, and therefore our demonstration that Rap1 plays a role in transducing the DDR signals at critically shortened telomeres into histone losses reveals the most detailed mechanism known to date.

Rap1 leads to histone losses in two ways. First, it represses histone gene expression by targeting the upstream promoter regions of the histone loci, thus contributing to global down-regulation of histones. Second, it contributes to site-specific losses in nucleosome occupancy at the promoters of NRTS that are up-regulated at senescence (as reflected by chromatin-immunoprecipitated histone H3 levels). It will be important in future studies to explore the detailed mechanisms underlying these two effects of Rap1, but there are already clues to possible mechanisms.

In the case of histone gene down-regulation, it is clear that Rap1 does not repress expression via recruitment of the Sir2/3/4 protein complex, and repression is not explained by increased nucleosome occupancy at the histone gene promoters. The regulation of histone gene expression in normal cells is under tight control and involves a large number of regulators, both positive (Spt10, Swi4, Mbp1, Rtt109, and the SWI/SNF complex) and negative (the HIR and RSC complexes, Asf1, and Rtt106) (Eriksson et al. 2012). Rap1 may either inhibit or facilitate the action of one or more of these regulators, for example, by competing with the binding of a positive regulator.

In the case of site-specific histone losses at up-regulated NRTS, nucleosome losses may simply be an indirect consequence of the elevated expression of these genes. However, we favor a more direct role for Rap1 in competing with nucleosomes for site occupancy, based on several long-standing and recent findings in wild-type cells. For example, Rap1 can interfere with nucleosome positioning and facilitate gene activation by the Gcn 4 transcription factor, which by itself cannot function efficiently at binding sites ensconced within a nucleosome (Yu and Morse 1999), and experimental depletion of Rap1 leads to rapid elevations in nucleosome occupancy selectively at sites to which it was previously bound (Ganapathi et al. 2011). Furthermore, Rap1-binding sites are enriched at the entry/exit points for the DNA wrapped around the majority of nucleosomes to which it binds, where it may gain access to relatively free DNA, thus weakening histone-DNA interactions, and indeed these nucleosomes display particularly low occupancy and high turnover rates (Dion et al. 2007; Koerber et al. 2009; Rhee and Pugh 2011). Finally, sites to which Rap1 binds with the longest residence time (i.e., slowest off rate) are those with the least nucleosome occupancy (Lickwar et al. 2012). Regardless of whether the competition between Rap1 and nucleosomes at up-regulated NRTS is direct or indirect, it clearly plays important roles in the regulation of gene expression in senescent cells.

Mammalian Rap1 might also have similar effects on chromatin, nucleosome occupancy, and gene expression. For example, overexpression of Trf2, which recruits hRap1 to DNA, can reduce nucleosome density within telomere chromatin, which suggests that the hRap1:Trf2 complex may modify chromatin (Galati et al. 2012). Also, the recent demonstrations that mammalian Rap1 not only localizes to telomeres but also can bind with some affinity to DNA itself, contribute to the transcriptional regulation of sites throughout the genome, and bind several histone proteins raise the possibility that mammalian Rap1 may contribute to changes in chromatin and gene expression in senescent cells (Martinez et al. 2010; Lee et al. 2011; Yang et al. 2011; Arat and Griffith 2012).

Our findings provide insight into how Rapl selectively targets NRTS. Many sites containing sequences to which Rap1 binds with optimal affinity in vitro are not occupied by Rap1 in wild-type cells, indicating the chromatin context contributes to Rap1 occupancy (Lieb et al. 2001). The promoters of NRTS are not enriched for optimal Rap1binding sites, but rather tend to contain hemisite plus linker sequences to which Rap1 binds selectively but with reduced affinity in vitro (Del Vescovo et al. 2004). In addition, the most highly enriched motif present within NRTS promoters is TTTTTTGCGC, which is similar to the so-called G/C-capped poly(dA:dT) tracts that normally associate with the centers of nucleosome-free regions in yeast promoters (Wu and $\mathrm{Li} 2010)$. Poly(dA:dT) tract length is inversely correlated with nucleosome stability (Segal and Widom 2009), and so we propose that the short tracts found within NRTS are not sufficient to exclude nucleosomes substantially in wild-type cells, but as histone levels decline at senescence, the local effects of these tracts are uncovered by a global shift in equilibrium toward nucleosome loss. Thus, nucleosome destabilization together with increased Rap1 availability and binding to nearby hemisites would conspire to drive the observed nucleosome losses selectively at NRTS.

Senescence is accompanied by the association of Rap1 with hundreds of new target loci along with increased Rap1 levels at most of the targets to which it normally localizes in wild-type cells (for additional analyses and discussion of the normal targets of Rap1, see the Supplemental Material, including Supplemental Fig. S11). This raises the following question: From where do these additional Rap1 proteins arise? Elevated levels of Rap1 are not the answer because total cell levels of Rapl remain relatively constant. It seems reasonable that as the telomere repeat tracts shorten with senescence, telomerebound Rap1 should be liberated. However, telomeres contain approximately one Rapl protein per 18 base pairs (bp) of DNA (Gilson et al. 1993), and if we assume that each of the 32 telomeres in a haploid cell loses, on average, 200-250 bp of DNA by senescence, this would liberate ony 350-450 Rap1 proteins, which may not be enough to account for $\sim 500$ NRTS along with increases at normal Rap1 targets. Another potential reservoir of Rap1 is provided by the subtelomeric regions, from which we found Rapl is lost at senescence; although normal subtelomeric levels of Rap1 have not been carefully measured, there are indications that they may be substantial. For example, this is illustrated by the dramatic delocalization of Rap1 from telomere-associated foci visualized by fluorescence microscopy in sir mutants 
(Gotta et al. 1996). Because Rap1 associates indirectly with subtelomeres via binding to nucleosome-bound Sir3 and Sir4 (Strahl-Bolsinger et al. 1997; Moretti and Shore 2001) and because the direct binding of Rap1 to telomere repeat DNA with $\mathrm{Kd} \sim 10^{-11} \mathrm{M}$ is presumably independent of Sir proteins, this dramatic loss suggests that a greater number of Rap1 proteins are associated with subtelomeric than telomeric sequences. The Sir proteins are known to delocalize from subtelomeres at senescence, as demonstrated by fluorescence microscopy (Straatman and Louis 2007) and as indicated by the increased acetylation of subtelomeric histone H4K16, which destabilizes Sir3 binding to nucleosomes (Kozak et al. 2010). Therefore, our finding that Rapl leaves subtelomeres at senescence is in keeping with previous observations. We also note that even though relocalization of the Sir silencing proteins from telomeres to other loci, either from engineered redistribution or following DNA damage, have been found to have important functional consequences (Maillet et al. 1996; Marcand et al. 1996; Martin et al. 1999), we did not detect roles for the Sir proteins at down-regulated targets of Rap1 (Supplemental Figs. S8, S11). In addition to delocalization of Rap1 from telomeres and subtelomeres at senescence, the increase in the number of Rapl-targeted loci may also reflect a shift in the general equilibrium from nucleoplasmic to chromosome-associated Rap1, perhaps aided by increased exposure of binding sites secondary to nucleosome losses.

Consistent with the new localization of Rap1 not being a simple mass action-based consequence of its liberation from shortened telomere repeat DNA, the loss of Rap1 from subtelomeres and its new localization at NRTS depend on the DDR kinase Mec1. However, many of these changes are unique to senescence and not just a generic stress or DDR (for comparisons of roles for Rap1 during senescence, DDR, and other stress responses, see the Supplemental Material, including Supplemental Figs. S12, S13; Supplemental Table S6). In addition, these events correlate with Mec1-dependent post-translational modification of Rap1, and the identity and potential functional role of such modification are currently under investigation. Furthermore, deletion of MEC1 delays senescence (Abdallah et al. 2009), consistent with the Mec1 dependence of Rapl action at senescence.

In the setting of critically shortened telomeres, what might be the purpose of a DDR-regulated redistribution of Rap1 leading to activation of stress response genes and down-regulation of histone genes? Although telomerase naturally maintains steady-state telomere length in yeast, telomere loss events can still occur, e.g., at broken replication forks, and this response might be of benefit in such cases. However, the response may be only one manifestation of a mechanism having broader importance for the repair of DNA breaks in other genomic regions. In cells lacking telomerase, critically shortened telomeres are similar to double-stranded breaks (DSBs) that are slowly repaired or are irreparable; i.e., DSBs that do not have a readily available homologous target sequence (e.g., a sister chromatid) or have no homologous target sequence from which to template HR-dependent repair. For example, both types of lesions can eventually translocate to the nuclear pore complex, where it is thought that checkpoint responses and alternative HR pathways are activated (Nagai et al. 2008; Khadaroo et al. 2009; Oza et al. 2009). Slowly repaired breaks have also been found recently to activate chromatin mobility of not only the break site itself, but apparently also other genomic regions, which is thought to enhance the search of the broken end for a homologous target (Dion et al. 2012; Miné-Hattab and Rothstein 2012). The increased mobility requires both Mec1 signaling and the action of the Ino80 chromatin remodeling complex, which can evict nucleosomes and may thus facilitate chromatin mobility (Neumann et al. 2012). Rap1-dependent stimulation of nucleosome losses at particular genomic sites together with down-regulation of global histone levels could contribute to this mechanism. This hypothesis is consistent with the similar patterns of NRTS gene expression in MMS-treated and senescent cells, including down-regulation of histone genes (Gasch et al. 2001), and indicates that roles for Rap1 in the repair of DNA breaks throughout the genome should be explored.

\section{Materials and methods}

Detailed methods are provided in the Supplemental Material.

\section{Yeast strains}

All strains are from the BY4741/2 background and are described in Supplemental Table S7.

\section{Senescence assays}

Senescence was performed by serial passage in liquid medium of spore products obtained from TLC1/tlc1 1 diploids. Comparisons of senescence in tlc1s mutants also possessing other genetic changes were performed using cells from diploids also heterozygous for the genetic change of interest (e.g., RAP1/rap1 DAmP), ensuring comparisons between cells inheriting telomeres of similar length and from the same epigenetic environment. Samples for mRNA expression and ChIP assays of senescent cells were obtained approximately five PDs prior to the growth nadir to avoid contributions from survivors of senescence.

\section{ChIP}

ChIP was performed as previously described (Kozak et al. 2010) using chromatin cross-linked with formaldehyde and sonicated to an average 100 - to $200-$ bp DNA fragment size.

\section{Acknowledgments}

We are grateful to S. Hershman for initial work on the project; to V. Geli, S. Berger, W. Dang, D. Churikov, E. Gilson, M. Kupiec, Y. Tzfati, K. Runge, P. Adams, R. Marmorstein, D. Schultz, V. Zakian, D. Shore, A. Sfeir, P. Lieberman, R. Greenberg, E. Brown, M. Wasik, and the members of the Johnson and Wang laboratories for discussions and encouragement; and to J. Tyler for generously providing yeast strains. This work was supported by National Institutes of Health grants P01-AG031862 (to F.B.J. and L.S.W.), R01-AG021521 (to F.B.J.), T32-AG000255 (to J.M.P.), and T32-HG000046 (to P.R.); a PA Tobacco Settlement Research 
Platt et al.

Award (to S.R.M. and F.B.J.); and an Ellison Medical Foundation/ AFAR Post-doctoral Fellowship (to J.J.W.).

\section{References}

Abdallah P, Luciano P, Runge KW, Lisby M, Géli V, Gilson E, Teixeira MT. 2009. A two-step model for senescence triggered by a single critically short telomere. Nat Cell Biol 11: 988-993.

Arat NÖ, Griffith JD. 2012. Human Rap1 interacts directly with telomeric DNA and regulates TRF2 localization at the telomere. J Biol Chem 287: 41583-41594.

Armanios M. 2013. Telomeres and age-related disease: How telomere biology informs clinical paradigms. I Clin Invest 123: 996-1002.

Baker DJ, Wijshake T, Tchkonia T, Lebrasseur NK, Childs BG, Van De Sluis B, Kirkland JL, Van Deursen JM. 2011. Clearance of p16Ink4a-positive senescent cells delays ageingassociated disorders. Nature 479: 1-6.

Benetti R, García-Cao M, Blasco MA. 2007. Telomere length regulates the epigenetic status of mammalian telomeres and subtelomeres. Nat Genet 39: 243-250.

Blasco MA, Lee H-W, Hande MP, Samper E, Lansdorp PM, DePinho RA, Greider CW. 1997. Telomere shortening and tumor formation by mouse cells lacking telomerase RNA. Mol Cell 91: 25-34.

Breslow DK, Cameron DM, Collins SR, Schuldiner M, StewartOrnstein J, Newman HW, Braun S, Madhani HD, Krogan NJ, Weissman JS. 2008. A comprehensive strategy enabling highresolution functional analysis of the yeast genome. Nat Methods 5: 711-718.

Buchman AR, Lue NF, Kornberg RD. 1988. Connections between transcriptional activators, silencers, and telomeres as revealed by functional analysis of a yeast DNA-binding protein. Mol Cell Biol 8: 5086-5099.

Buck MJ, Lieb JD. 2006. A chromatin-mediated mechanism for specification of conditional transcription factor targets. Nat Genet 38: 1446-1451.

Campisi J. 1997. The biology of replicative senescence. Eur I Cancer 33: 703-709.

Campisi J. 2013. Aging, cellular senescence, and cancer. Annu Rev Physiol 75: 685-705.

Capper R, Britt-Compton B, Tankimanova M, Rowson J, Letsolo B, Man S, Haughton M, Baird DM. 2007. The nature of telomere fusion and a definition of the critical telomere length in human cells. Genes Dev 21: 2495-2508.

Del Vescovo V, De Sanctis V, Bianchi A, Shore D, Di Mauro E, Negri R. 2004. Distinct DNA elements contribute to Raplp affinity for its binding sites. J Mol Biol 338: 877-893.

Dion MF, Kaplan T, Kim M, Buratowski S, Friedman N, Rando OJ. 2007. Dynamics of replication-independent histone turnover in budding yeast. Science 315: 1405-1408.

Dion V, Kalck V, Horigome C, Towbin BD, Gasser SM. 2012. Increased mobility of double-strand breaks requires Mec1, Rad9 and the homologous recombination machinery. Nat Cell Biol 14: 502-509.

Enomoto S, Glowczewski L, Berman J. 2002. MEC3, MEC1, and DDC2 are essential components of a telomere checkpoint pathway required for cell cycle arrest during senescence in Saccharomyces cerevisiae. Mol Biol Cell 13: 2626-2638.

Eriksson PR, Ganguli D, Nagarajavel V, Clark DJ. 2012. Regulation of histone gene expression in budding yeast. Genetics 191: $7-20$

Feser J, Truong D, Das C, Carson JJ, Kieft J, Harkness T, Tyler JK. 2010. Elevated histone expression promotes life span extension. Mol Cell 39: 724-735.
Freeman K, Gwadz M, Shore D. 1995. Molecular and genetic analysis of the toxic effect of RAP1 overexpression in yeast. Genetics 141: 1253-1262.

Galati A, Magdinier F, Colasanti V, Bauwens S, Pinte S, Ricordy R, Giraud-Panis M-J, Pusch MC, Savino M, Cacchione S, et al. 2012. TRF2 controls telomeric nucleosome organization in a cell cycle phase-dependent manner. PLOS ONE 7: e34386.

Ganapathi M, Palumbo MJ, Ansari SA, He Q, Tsui K, Nislow C, Morse RH. 2011. Extensive role of the general regulatory factors, Abf1 and Rap1, in determining genome-wide chromatin structure in budding yeast. Nucleic Acids Res 39: 2032-2044.

Gasch AP, Huang M, Metzner S, Botstein D, Elledge SI, Brown PO. 2001. Genomic expression responses to DNA-damaging agents and the regulatory role of the yeast ATR homolog Meclp. Mol Biol Cell 12: 2987-3003.

Gilson E, Roberge M, Giraldo R, Rhodes D, Gasser SM. 1993. Distortion of the DNA double helix by RAP1 at silencers and multiple telomeric binding sites. J Mol Biol 231: 293-310.

Gotta M, Laroche T, Formenton A, Maillet L, Scherthan H, Gasser SM. 1996. The clustering of telomeres and colocalization with Rap1, Sir3, and Sir4 proteins in wild-type Saccharomyces cerevisiae. J Cell Biol 134: 1349-1363.

Hackett JA, Feldser DM, Greider CW. 2001. Telomere dysfunction increases mutation rate and genomic instability. Cell 106: $275-286$.

Harbison CT, Gordon DB, Lee TI, Rinaldi NJ, Macisaac KD, Danford TW, Hannett NM, Tagne J-B, Reynolds DB, Yoo J, et al. 2004. Transcriptional regulatory code of a eukaryotic genome. Nature 431: 99.

Heinz S, Benner C, Spann N, Bertolino E, Lin YC, Laslo P, Cheng JX, Murre C, Singh H, Glass CK. 2010. Simple combinations of lineage-determining transcription factors prime cisregulatory elements required for macrophage and B cell identities. Mol Cell 38: 576-589.

Herbig U, Jobling WA, Chen BPC, Chen DJ, Sedivy JM. 2004. Telomere shortening triggers senescence of human cells through a pathway involving ATM, p53, and p21(CIP1), but not p16(INK4a). Mol Cell 14: 501-513.

IJpma AS, Greider CW. 2003. Short telomeres induce a DNA damage response in Saccharomyces cerevisiae. Mol Biol Cell 14: 987-1001.

Johnson FB, Marciniak RA, McVey M, Stewart SA, Hahn WC, Guarente L. 2001. The Saccharomyces cerevisiae WRN homolog Sgslp participates in telomere maintenance in cells lacking telomerase. EMBO J 20: 905-913.

Khadaroo B, Teixeira MT, Luciano P, Eckert-Boulet N, Germann SM, Simon MN, Gallina I, Abdallah P, Gilson E, Géli V, et al. 2009. The DNA damage response at eroded telomeres and tethering to the nuclear pore complex. Nat Cell Biol 11: 980987.

Klein F, Laroche T, Cardenas ME, Hofmann JF, Schweizer D, Gasser SM. 1992. Localization of RAP1 and topoisomerase II in nuclei and meiotic chromosomes of yeast. J Cell Biol 117: 935-948.

Koerber RT, Rhee HS, Jiang C, Pugh BF. 2009. Interaction of transcriptional regulators with specific nucleosomes across the Saccharomyces genome. Mol Cell 35: 889-902.

Konig P, Giraldo R, Chapman L, Rhodes D. 1996. The crystal structure of the DNA-binding domain of yeast RAP1 in complex with telomeric DNA. Cell 85: 125-136.

Kozak ML, Chavez A, Dang W, Berger SL, Ashok A, Guo X, Johnson FB. 2010. Inactivation of the Sas2 histone acetyltransferase delays senescence driven by telomere dysfunction. $E M B O$ J 29: 158-170. 
Kyrion G, Liu K, Liu C, Lustig AJ. 1993. RAP1 and telomere structure regulate telomere position effects in Saccharomyces cerevisiae. Genes Dev 7: 1146-1159.

Laroche T, Martin SG, Tsai-Pflugfelder M, Gasser SM. 2000. The dynamics of yeast telomeres and silencing proteins through the cell cycle. I Struct Biol 129: 159-174.

Lee O-H, Kim H, He Q, Baek HI, Yang D, Chen L-Y, Liang J, Chae HK, Safari A, Liu D, et al. 2011. Genome-wide YFP fluorescence complementation screen identifies new regulators for telomere signaling in human cells. Mol Cell Proteomics 10: M110.001628.

Lescasse R, Pobiega S, Callebaut I, Marcand S. 2013. Endjoining inhibition at telomeres requires the translocase and polySUMO-dependent ubiquitin ligase Uls1. EMBO / 32: 805815.

Lickwar CR, Mueller F, Hanlon SE, McNally JG, Lieb JD. 2012. Genome-wide protein-DNA binding dynamics suggest a molecular clutch for transcription factor function. Nature 484: 251-255.

Lieb JD, Liu X, Botstein D, Brown PO. 2001. Promoter-specific binding of Rapl revealed by genome-wide maps of proteinDNA association. Nat Genet 28: 327-334.

Lundblad V, Blackburn EH. 1993. An alternative pathway for yeast telomere maintenance rescues est1- senescence. Cell 73: 347-360.

Lundblad V, Szostak JW. 1989. A mutant with a defect in telomere elongation leads to senescence in yeast. Cell 57: 633-643.

Maillet L, Boscheron C, Gotta M, Marcand S, Gilson E, Gasser SM. 1996. Evidence for silencing compartments within the yeast nucleus: A role for telomere proximity and Sir protein concentration in silencer-mediated repression. Genes Dev 10: 1796-1811.

Marcand S, Buck SW, Moretti P, Gilson E, Shore D. 1996. Silencing of genes at nontelomeric sites in yeast is controlled by sequestration of silencing factors at telomeres by Rap 1 protein. Genes Dev 10: 1297-1309.

Marcand S, Gilson E, Shore D. 1997. A protein-counting mechanism for telomere length regulation in yeast. Science 275: 986-990.

Maringele L, Lydall D. 2004. Telomerase- and recombinationindependent immortalization of budding yeast. Genes Dev 18: $2663-2675$.

Martin SG, Laroche T, Suka N, Grunstein M, Gasser SM. 1999. Relocalization of telomeric $\mathrm{Ku}$ and SIR proteins in response to DNA strand breaks in yeast. Cell 97: 621-633.

Martinez P, Thanasoula M, Carlos AR, Gómez-López G, Tejera AM, Schoeftner S, Dominguez O, Pisano DG, Tarsounas M, Blasco MA. 2010. Mammalian Rap1 controls telomere function and gene expression through binding to telomeric and extratelomeric sites. Nat Cell Biol 12: 768-780.

Miné-Hattab J, Rothstein R. 2012. Increased chromosome mobility facilitates homology search during recombination. Nat Cell Biol 14: 510-517.

Moretti P, Shore D. 2001. Multiple interactions in Sir protein recruitment by Raplp at silencers and telomeres in yeast. Mol Cell Biol 21: 8082-8094.

Mukherjee S, Berger MF, Jona G, Wang XS, Muzzey D, Snyder M, Young RA, Bulyk ML. 2004. Rapid analysis of the DNAbinding specificities of transcription factors with DNA microarrays. Nat Genet 36: 1331-1339.

Nagai S, Dubrana K, Tsai-Pflugfelder M, Davidson MB, Roberts TM, Brown GW, Varela E, Hediger F, Gasser SM, Krogan NJ. 2008. Functional targeting of DNA damage to a nuclear poreassociated SUMO-dependent ubiquitin ligase. Science 322: 597-602.
Nautiyal S, DeRisi JL, Blackburn EH. 2002. The genome-wide expression response to telomerase deletion in Saccharomyces cerevisiae. Proc Nat1 Acad Sci 99: 9316-9321.

Negrini S, Ribaud V, Bianchi A, Shore D. 2007. DNA breaks are masked by multiple Rap1 binding in yeast: Implications for telomere capping and telomerase regulation. Genes Dev 21: 292-302.

Neumann FR, Dion V, Gehlen LR, Tsai-Pflugfelder M, Schmid R, Taddei A, Gasser SM. 2012. Targeted INO80 enhances subnuclear chromatin movement and ectopic homologous recombination. Genes Dev 26: 369-383.

O'Sullivan RJ, Kubicek S, Schreiber SL, Karlseder J. 2010. Reduced histone biosynthesis and chromatin changes arising from a damage signal at telomeres. Nat Struct Mol Biol 17: 1218-1225.

Oza P, Jaspersen SL, Miele A, Dekker J, Peterson CL. 2009. Mechanisms that regulate localization of a DNA doublestrand break to the nuclear periphery. Genes Dev 23: 912927.

Palladino F, Laroche T, Gilson E, Axelrod A, Pillus L, Gasser SM. 1993. SIR3 and SIR4 proteins are required for the positioning and integrity of yeast telomeres. Cell 75: 543-555.

Pardo B, Marcand S. 2005. Rap1 prevents telomere fusions by nonhomologous end joining. EMBO I 24: 3117-3127.

Putnam CD, Jaehnig EJ, Kolodner RD. 2009. Perspectives on the DNA damage and replication checkpoint responses in Saccharomyces cerevisiae. DNA Repair (Amst) 8: 974982.

Rhee HS, Pugh BF. 2011. Comprehensive genome-wide proteinDNA interactions detected at single-nucleotide resolution. Cell 147: 1408-1419.

Ritchie KB, Mallory JC, Petes TD. 1999. Interactions of TLC1 (which encodes the RNA subunit of telomerase), TEL1, and MEC1 in regulating telomere length in the yeast Saccharomyces cerevisiae. Mol Cell Biol 19: 6065-6075.

Sabourin M, Tuzon CT, Zakian VA. 2007. Telomerase and Tellp preferentially associate with short telomeres in S. cerevisiae. Mol Cell 27: 550-561.

Schaetzlein S, Kodandaramireddy NR, Ju Z, Lechel A, Stepczynska A, Lilli DR, Clark AB, Rudolph C, Kuhnel F, Wei K, et al. 2007. Exonuclease-1 deletion impairs DNA damage signaling and prolongs lifespan of telomere-dysfunctional mice. Cell 130: $863-877$.

Schawalder SB, Kabani M, Howald I, Choudhury U, Werner M, Shore D. 2004. Growth-regulated recruitment of the essential yeast ribosomal protein gene activator Ifh1. Nature 432: 1058.

Segal E, Widom J. 2009. Poly(dA:dT) tracts: Major determinants of nucleosome organization. Curr Opin Struct Biol 19: 6571.

Spellman PT, Sherlock G, Zhang MQ, Iyer VR, Anders K, Eisen MB, Brown PO, Botstein D, Futcher B. 1998. Comprehensive identification of cell cycle-regulated genes of the yeast Saccharomyces cerevisiae by microarray hybridization. Mol Biol Cell 9: 3273-3297.

Straatman KR, Louis EJ. 2007. Localization of telomeres and telomere-associated proteins in telomerase-negative Saccharomyces cerevisiae. Chromosome Res 15: 1033-1050.

Strahl-Bolsinger S, Hecht A, Luo K, Grunstein M. 1997. SIR2 and SIR4 interactions differ in core and extended telomeric heterochromatin in yeast. Genes Dev 11: 83-93.

Tomar RS, Zheng S, Brunke-Reese D, Wolcott HN, Reese JC. 2008. Yeast Rap1 contributes to genomic integrity by activating DNA damage repair genes. EMBO J 27: 1575-1584.

Tornow J, Zeng X, Gao W, Santangelo GM. 1993. GCR1, a transcriptional activator in Saccharomyces cerevisiae, com- 
Platt et al.

plexes with RAP1 and can function without its DNA binding domain. EMBO J 12: 2431-2437.

Ungar L, Yosef N, Sela Y, Sharan R, Ruppin E, Kupiec M. 2009. A genome-wide screen for essential yeast genes that affect telomere length maintenance. Nucleic Acids Res 37: 38403849.

Vignais ML, Huet J, Buhler JM, Sentenac A. 1990. Contacts between the factor TUF and RPG sequences. I Biol Chem 265: 14669-14674.

Vodenicharov MD, Laterreur N, Wellinger RJ. 2010. Telomere capping in non-dividing yeast cells requires Yku and Rap1. EMBO J 29: 3007-3019.

Wu R, Li H. 2010. Positioned and G/C-capped poly(dA:dT) tracts associate with the centers of nucleosome-free regions in yeast promoters. Genome Res 20: 473-484.

Wyrick JI, Holstege FC, Jennings EG, Causton HC, Shore D, Grunstein M, Lander ES, Young RA. 1999. Chromosomal landscape of nucleosome-dependent gene expression and silencing in yeast. Nature 402: 418-421.

Yang D, Xiong Y, Kim H, He Q, Li Y, Chen R, Songyang Z. 2011. Human telomeric proteins occupy selective interstitial sites. Cell Res 21: 1013-1027.

Yu L, Morse RH. 1999. Chromatin opening and transactivator potentiation by RAP1 in Saccharomyces cerevisiae. Mol Cell Biol 19: 5279-5288.

Zhao Y, McIntosh KB, Rudra D, Schawalder S, Shore D, Warner JR. 2006. Fine-structure analysis of ribosomal protein gene transcription. Mol Cell Biol 26: 4853-4862.

Zwerschke W, Mazurek S, Stöckl P, Hutter E, Eigenbrodt E, Jansen-Durr P. 2003. Metabolic analysis of senescent human fibroblasts reveals a role for AMP in cellular senescence. Biochem J 376: 403-411. 


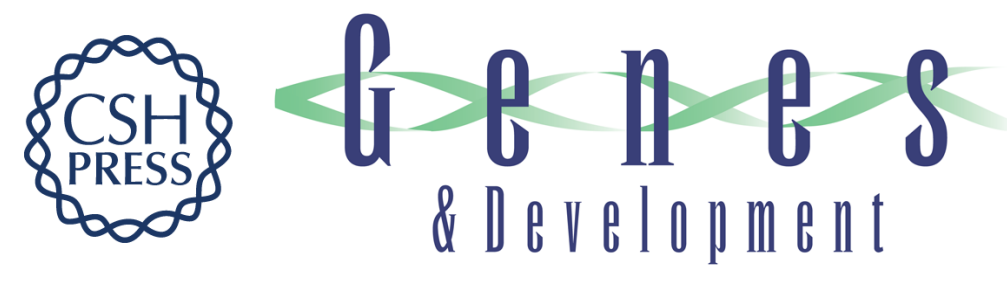

\section{Rap1 relocalization contributes to the chromatin-mediated gene expression profile and pace of cell senescence}

Jesse M. Platt, Paul Ryvkin, Jennifer J. Wanat, et al.

Genes Dev. 2013, 27: originally published online June 11, 2013

Access the most recent version at doi:10.1101/gad.218776.113

\section{Supplemental http://genesdev.cshlp.org/content/suppl/2013/06/04/gad.218776.113.DC1 Material}

References This article cites 81 articles, 31 of which can be accessed free at: http://genesdev.cshlp.org/content/27/12/1406.full.html\#ref-list-1

\section{License}

Email Alerting

Receive free email alerts when new articles cite this article - sign up in the box at the top Service

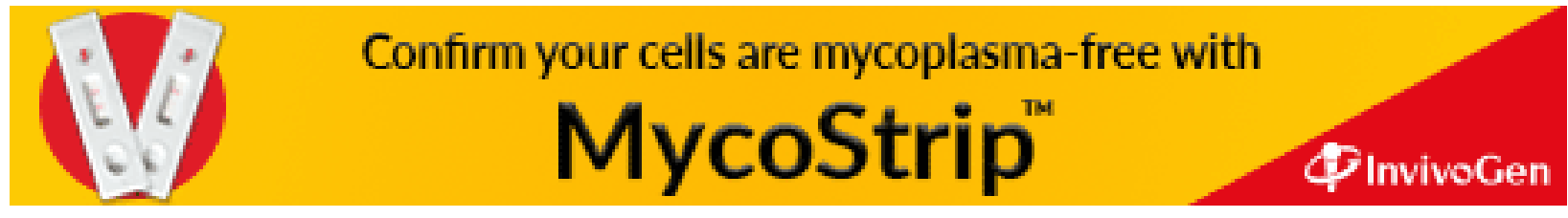

